\title{
The Relationship Between Cognitive and Affective Dimensions of Reading Self- Concept With Reading Achievement in English and Russian
}

Journal of Advanced Academics

$1-30$

(C) The Author(s) 2021

Article reuse guidelines: sagepub.com/journals-permissions DOI: 10.1 I 77/1932202X21995978 journals.sagepub.com/home/joaa

(SAGE

\section{Könül Karimova' (iD) and Benő Csapó ${ }^{2,3}$}

\begin{abstract}
This study aimed to evaluate whether cognitive and affective dimensions of reading self-concepts in English and Russian are distinct constructs and to examine whether the relationships among cognitive and affective variables are invariant across gender. A total of 349 tenth-grade Azeri students were selected from 12 schools in Baku, Azerbaijan. This study adapted the Self-Description Questionnaire and Cényelvi mérés for assessment of reading self-concepts and achievements in two foreign languages. The results of structural equation modeling demonstrated that cognitive and affective self-concepts were independent, but strongly interrelated constructs. The separated components of the reading self-concept construct showed a more explicit structure than a conflated model. The relationships among cognitive and affective self-concepts with achievements in the reading domain were invariant across gender. The results of this study can encourage future research on the examination of more domain-specific self-concepts that conceptualizes twofold multidimensional structure.
\end{abstract}

\section{Keywords}

cognitive and affective dimensions, reading achievement, reading self-concept, English, Russian, gender

\footnotetext{
'University of Szeged, Hungary

${ }^{2}$ Institute of Education, University of Szeged, Hungary

${ }^{3}$ MTA-SZTE Research Group on the Development of Competencies, Hungary

\section{Corresponding Author:}

Könül Karimova, Graduate Doctoral School of Educational Sciences, University of Szeged, Petőfi Sgt. 30-34, Szeged H-6722, Hungary.

Email: konulkerimova@edu.u-szeged.hu
} 
Psychologists defined self-concept as a person's perceptions of the self (Shavelson \& Marsh, 1986). Proposed classical self-concept theories (Shavelson et al., 1976) conceptualized self-concept as a multidimensional construct. In Shavelson's model, general self-concept appeared at the apex and consisted of academic and nonacademic self-concepts. General academic self-concept is divided into more specific subject areas (e.g., mathematics). To explain the relationship between subject-specific selfconcepts and achievements, Marsh and collaborators (Marsh, 1986; Marsh et al., 2006; Marsh \& Hau, 2004) developed the internal/external (I/E) frame of reference model. They found that individuals held separate frames of reference; the same measures of academic achievement resulted in different academic self-concepts. Marsh and Shavelson (1985) found a weak or no relation between mathematics and verbal self-concepts, although mathematics and verbal performances were revealed to be substantially related.

The further differentiability of academic self-concept into cognitive and affective components is one of the most intriguing questions of self-concept research (Arens et al., 2011). Although, over the past decades, the issue has been extensively studied (e.g., Abu-Hilal et al., 2013; Bong \& Skaalvik, 2003; Deci \& Ryan, 2000; Eccles \& Wigfield, 1995; Marsh et al., 1999), it has not been examined sufficiently within the reading domain, specifically within a foreign language domain. However, as academic self-concept is domain-specific (Marsh et al., 2006, 2020; Möller et al., 2011), more research is necessary to examine cognitive and affective components of self-concept within specific domains. Thus, considering that there is a shortage of studies that focus on twofold multidimensionality of self-concept within the reading domain, the present study aims to investigate further multidimensionality of reading self-concept by exploring cognitive and affective dimensions and its relation with reading achievement in English and Russian.

\section{The Relation Between Academic Achievement and Self- Concept}

More than 30 years ago, researchers (Calsyn \& Kenny, 1977; Hansford \& Hattie, 1982; Marsh \& Hattie, 1996) extensively studied the relationship between achievement and self-concept to find empirical support for the positive association between two variables. As a result of the studies, the skill development model and the selfenhancement model were developed. The self-enhancement model proposed that self-concept was a primary prerequisite of achievement resulting in more engagement and effort in domain-specific activities, which led to higher performance (Marsh \& Yeung, 1997; Valentine et al., 2004). Hence, the proposition of this model suggested that the main focus of educational interventions should be the enhancement of self-concept. Alternatively, the skill development model assumed that selfconcept in a specific domain is a consequence of achievement in that domain, which was explained by social comparisons (Marsh \& Craven, 2006; Möller \& Pohlmann, 2010). 
The development of the internal/external frame of reference model (Marsh, 1986; Marsh \& Shavelson, 1985) was due in part to social comparison theory and the skill development model. The $\mathrm{I} / \mathrm{E}$ frame of reference model implied that achievement in one subject domain positively predicted self-concept in that particular domain. However, performance in one domain (e.g., mathematics) negatively predicted selfconcept in a different domain. Although achievement scores of mathematics and language were strongly correlated, academic self-concepts in noncorresponding domains were hardly related. Research (see Wigfield \& Karpathian, 1991) on the multidimensional nature of self-concept has defined that domain-specificity of self-concept did not only relate to generic domains such as verbal and mathematics but also to more specific differentiation within domains (e.g., verbal domain). For example, Schiefele et al. (2012) assumed reading self-concept as a subcomponent of verbal self-concept. $\mathrm{Xu}$ et al. (2013) extended the classic I/E model by contrasting the mathematics domain with two verbal domains (Chinese as a native language; English as a foreign language) in combination with language instruction (English or Chinese) and found that native and foreign languages did not show contrast with each other in the formation of academic self-concept, but mathematics self-concept was negatively predicted by achievements in both verbal domains, whereas both verbal self-concepts were negatively predicted by mathematics achievement.

Marsh et al. (2020) studied psychological comparison processes by integrating social and dimensional comparison theories, which synthesized five paradoxical frame-of-reference and contextual effects in self-concept formation that occurred at different levels over 68 countries and provided theoretical and empirical support for psychological comparison processes that influenced self-perceptions and their relation to distal outcomes. They reported two comparison processes: The first was the dimensional comparison process that implied that effects on mathematics self-concept are positive for mathematics achievement but negative for verbal achievement, and the second was a social comparison process that implied that the effects on mathematics self-concept are negative for school-average mathematics achievement (big-fish-little-pond effect), country-average achievement (paradoxical cross-cultural effect), and being young relative to year in school, but are positive for school-average verbal achievement (big-fish-little-pond effect - compensatory effect).

Arens et al. (2020) examined German 10th-grade students' academic self-concepts and reviewed methodologies that are considered the most central models depicting the structure of academic self-concept: higher-order factor model, the Marsh-Shavelson model, the nested Marsh-Shavelson model, a bifactor representation based on exploratory structural equation modeling, and a first-order factor model. They reported elaborations of these models representing the theoretical assumptions on the structure of academic self-concept and indicated their inherent psychometric properties. Arens et al. (2020) found that each academic self-concept model had its advantages and limitations depending on different research questions and recommended careful consideration in selecting a specific academic self-concept model. Therefore, most studies on self-concept research focused on academic self-concept, its structure, and relationships with achievement, disregarding more subject-specific domains of academic 
self-concept. Considering the shortage of studies in subject-specific domains of academic self-concept, the present study focused on reading self-concepts of the verbal domain.

\section{Achievement and Self-Concept Within a Reading Domain}

Being the overall self-perception of oneself as a reader (Conradi et al., 2014), reading self-concept is related to reading motivation (Chapman \& Tunmer, 2003; Kasperski et al., 2016; Katzir et al., 2009), which has been a significant determinant of reading achievement. Morgan and Fuchs (2007) understood competence beliefs as estimates of one's ability level in each activity and defined competence beliefs as a central aspect of reading motivation. This definition corresponded to the comprehension of self-concept definition. Most studies (Retelsdorf et al., 2011; Wigfield \& Guthrie, 1997) have defined reading self-concept as a significant predictor of reading achievement. Individuals who had higher perceptions of competence beliefs assumed to show better performance in reading practice. In contrast, individuals with low levels of reading self-concept are believed to have poor results in reading tasks. Only a few studies (Arens et al., 2014; Arens \& Jansen, 2016; Aunola et al., 2002; Chapman \& Tunmer, 1997; Retelsdorf et al., 2014) have examined the relationship between reading self-concept and reading achievement. However, none of these studies has focused on two foreign languages and their cognitive and affective dimensions.

Aunola et al. (2002) conducted longitudinal studies to find a reciprocal relationship between reading self-concept and reading achievement and found a significant relationship between the two variables. Arens et al. (2014) conducted three studies of German students' reading and German (native language) self-concepts to examine whether these two variables were similar or separate constructs. They found significant correlations between the competence and affective components of reading selfconcept with reading achievement (competence: $r=.28, p<.01$; affect: $r=.26, p<$ $.01)$. This evidence supported the twofold multidimensional nature of reading self-concept.

Further to reveal the multidimensional nature of verbal self-concepts, Arens and Jansen (2016) studied the relationships among skill-specific facets (reading, listening, speaking, and writing) and their corresponding domains in English, French, and German and found that students' reading test scores similarly related to reading selfconcept compared with the other skill-specific facets (English: $r=.47, p<.001$; French: $r=.52, p<.001)$. However, German reading self-concept demonstrated higher correlations to the reading score $(r=.45 ; p<.001)$ than the other self-concept facets. The study considered only cognitive items to measure students' self-concepts in four skill-specific areas. There are a vast number of studies that advocate the usage of the items related to the affective component of self-concept (e.g., Abu-Hilal et al., 2013; Pinxten et al., 2014; Yang et al., 2014). 


\section{Separation of Self-Concept Into Cognitive and Affective Components}

Although Shavelson et al. (1976) argued that cognitive and affective components of self-concept could not be distinguished into separate components, most studies have focused on the self-perception of the cognitive more than the affective dimension. Eccles and Wigfield (1995) studied adolescents' achievement-related beliefs and selfperceptions and found the distinction between task values and ability perception factors. Chapman and Tunmer (1995) examined the development of reading self-concept in young children and defined three subcomponents: perceptions of competence in reading, perceptions of difficulty with reading, and attitudes toward reading. They revealed that reading comprehension is similarly related to the competence component $(r=.43)$ and attitudes toward reading $(r=.40)$ in Year 5. Nonetheless, in Year 4, they found a strong correlation between reading comprehension with competence $(r=.40)$ compared with attitudes toward reading $(r=.17)$. Marsh et al. (1999) emphasized the multidimensionality nature of academic self-concept, suggesting that models with competence and affect separation showed better fit. Furthermore, Yeung and Wong (2004) studied teachers' academic self-concept in mathematics and three languages (English, Cantonese, and Mandarin). They found a low correlation between English and Mandarin self-concepts $(r=.09)$, negative correlations between English and Cantonese $(r=-.19)$, and Cantonese and Mandarin self-concepts $(r=-.11)$.

Extensive research (Marsh et al., 2014, 2012; Marsh \& Hau, 2004; Marsh \& Köller, 2004; Möller et al., 2011; Xu et al., 2013) on the multidimensionality of self-concept has found a weak relation between mathematics and verbal self-concepts, and recent research (Arens et al., 2011) has extended domain-specificity of academic self-concept to the distinction between cognitive and affective components. Möller et al. (2009) conducted an extensive meta-analysis based on 69 data sets $(n=125,308)$ and found a positive correlation between matching domains (verbal achievement and selfconcept: $r=.49$; mathematics achievement and self-concept: $r=.61$, whereas mathematics achievement negatively predicted verbal self-concept $(r=-.21)$ and verbal achievement negatively predicted mathematics self-concept $(r=-.27)$. Arens et al. (2011) studied third- to sixth-grade $(n=1,958)$ students' cognitive and affective components of mathematics and German (native language) self-concepts and found a stronger correlation between the cognitive component of self-concept and achievement (mathematics: $r=.61$; verbal: $r=.63$ ) than the affective component (mathematics: $r=.37$; verbal: $r=.33$ ) within and across corresponding domains, providing support for further separation of cognitive and affective components of academic self-concept.

A twofold multidimensional structure of academic self-concept has also been applied to students of various countries and cultures (e.g., Indigenous Australian: Arens, Bodkin-Andrews, et al. 2014; German: Arens et al., 2011; French-Canadian: Marsh \& Ayotte, 2003; Anglo-Saxon and Arab: Marsh et al., 2012). Yang et al. (2014) investigated the multidimensionality of academic self-concept with Chinese vocational students. They revealed support for the twofold multidimensionality of 
academic self-concept to these students' native and nonnative languages. Abu-Hilal et al. (2013) examined the cognitive and affective separation of academic self-concept within mathematics and science domains with Saudi eighth-graders. They found that the internal structure of mathematics and science self-concepts was more explicit when cognitive and affective components within the two domains were separated. However, there is a shortage of studies that focused on the twofold multidimensionality of reading self-concept in two foreign languages.

\section{Gender Invariance}

Most studies (Arens et al., 2013; Arens \& Jansen, 2016; Jacobs et al., 2002) on the multidimensional structure of self-concept have emphasized the examination of gender differences as an essential contribution to validating this structure, specifically within specific language self-concepts. Han (2019) studied gender differences in the relationship between mathematics self-concept and achievement and found that boys had higher perceptions in the cognitive component of mathematics self-concept than girls. The examination of gender effects might help clarify the separation of cognitive and affective components of reading self-concept. The differential of gender effects would reveal the different perceptions of both genders related to cognitive and affective components, advocating for multidimensionality within reading self-concept.

\section{Language Education in Azerbaijan}

Being located between Europe and Asia, Azerbaijan was one of the republics of the former Soviet Union, with 10 million people. About $94 \%$ of the population are ethnic Azerbaijanis, and various minorities (Russians, Jews, Lezgis, and Talyshes) also inhabit the country. Although the country has been bilingual (Azerbaijani and Russian), throughout Soviet times Russian has been dominant and English has been taught as a part of the secondary school curriculum. After gaining independence, Azerbaijani has become the only used official language of the republic (Shafiyeva \& Kennedy, 2010). As the grammar-translation method was considered an effective way for language teaching during Soviet times, students' language skills could not be developed. Therefore, after launching a new conception of general secondary education (a national curriculum) in 2006, the new curriculum of state standards of specific subject programs was proposed in 2010 (Ministry of Education of Azerbaijan Republic, 2010). Furthermore, the modified curriculum for detail improvements was introduced in 2012 (Ministry of Education of Azerbaijan Republic, 2012), making the teaching of two foreign languages mandatory across grades.

Furthermore, the development of the culture of Azerbaijan is influenced by Iranian, Turkic, and Caucasian heritage, and including Russian heritage as a result of being a former member of the Soviet state. However, nowadays Western culture is dominant in the republic, but the Eastern historical influence remains in everyday life, particularly in education. The impact of the socialization process on education resulted in students, especially boys, to be less critical and have higher perceptions of ability than 
can be expected from their achievements. Lafontine et al. (2019) studied the competence and difficulty dimensions of reading self-concept of 48 countries from the Progress in International Reading Literacy Study (PIRLS). They found an invariant relationship between reading self-concept and achievement across countries, indicating the two-dimensional structure showed a better model fit. In their study, they found a weak correlation between the competence component of reading self-concept and reading achievement $(r=.18)$ for Azerbaijan. However, they did not include the affective component of reading self-concept.

The education system in Azerbaijan consists of two phases: basic education (primary: first to fourth grades; general secondary: fifth to ninth grades) and complete secondary education (10th-11th grades). After compulsory basic education, students have a chance to choose among various opportunities such as entry into complete secondary education, vocational education and training, distance learning, or direct admission to employment (Ministry of Education of Azerbaijan Republic, 2010). In the first grade, the first foreign language (English) is taught $3 \mathrm{hr}$ per week, whereas the second foreign language is taught an hour per week in the fifth grade.

\section{The Present Study}

Previous studies have provided evidence of the twofold multidimensional structure of academic and language self-concepts (Arens et al., 2011; Yang et al., 2014). However, there is a lack of research that focuses on the multidimensional structure of reading self-concept in two foreign languages. Research (e.g., Arens et al., 2014) has studied the reading self-concept of the native language. This study aims to further corroborate this research by providing new empirical evidence; it is a question of whether the twofold multidimensionality of reading self-concept generalizes or varies for both foreign languages. This study examines

a. the structure of reading self-concept, comparing conflated models of reading self-concepts in two foreign languages to examine the conflation of cognitive and affective constructs with separated models of reading self-concept, which would demonstrate the twofold multidimensionality of reading self-concepts in English and Russian;

b. the I/E frame of reference model within reading self-concept and hypothesizing domain-specificity of reading self-concept will be consistent with the I/E frame of reference model. Separating reading self-concept into cognitive and affective components would produce more explicit relationships both within network and between network;

c. the relationships between reading achievements in two target languages and reading self-concepts, and assuming the stronger correlation between cognitive components of reading self-concepts and reading performance in the corresponding domain than noncorresponding and corresponding affective components of reading self-concepts; and 
d. the invariance test of the I/E model of first-order factors based on cognitive and affective components of reading self-concept and reading achievement in English and Russian across gender. This analysis would assess the extent to which the I/E model differs across gender if factor loadings and item intercepts would constrain to be equivalent across gender.

\section{Method}

\section{Sample}

The data were collected in the winter of 2020. The total sample consisted of 349 Baku secondary school students (54.7\% boys, 44.7\% girls) in Grade 10 (12 schools of all 12 administrative districts) who completed online tests in reading achievement of English and Russian, and a questionnaire in Azerbaijani. The mean age of the sample was $15.28(S D=0.54$; range $=14-18)$ years. As students are expected to reach the B1 level at the end of their school studies, the present study selected 10th grade as adequate to be the target group of the research. Eleventh grade in Azerbaijan is considered the final school year. The eDia (electronic diagnostic assessment) online platform for online assessment was applied to facilitate data collection (Csapó \& Molnár, 2019). Schools were selected by the Baku Educational Department based on two criteria: (a) students should enroll for both target languages (English as the first language and Russian as the second language), and (b) schools that meet the first criteria were then moved to a second round of selection that was based on a random number generator. As the results of achievement tests would be the main focus of teachers' and instructors' interests for comparing their results with school grades, students' participation in these tests was mandatory, but students' participation in the survey was voluntary. Parental consent was required for a student's participation.

\section{Procedure}

All participants were informed about the anonymous and confidential usage of their responses. Before administration of the instruments, a brief description of the purpose of the present study was introduced by the author. Measures of this study were available on an online platform and each student was provided with passwords to access this platform and guarantee confidential data collection. Students used the same password for all achievement tests and a questionnaire. Passwords consisted of nine-digit numbers, such as 191012613, which students entered on the webpage. First, reading achievement tests in English were administered lasting nearly $50 \mathrm{~min}$. After a 15 -min break, reading achievement tests in Russian were administered lasting nearly 50 min. Similarly, after a 15-min break, the reading self-concept questionnaire was completed.

\section{Instruments}

Achievement. The present study adapted achievement tests in reading (Cényelvi mérés, 2013/2014), which were developed by Hungarian experts and teachers. Based on 
Table I. The Online English and Russian Reading Comprehension Tests.

\begin{tabular}{|c|c|c|c|c|c|}
\hline \multirow{2}{*}{$\begin{array}{l}\text { No. of } \\
\text { tests }\end{array}$} & \multirow[b]{2}{*}{ Task } & \multirow[b]{2}{*}{ Input text } & \multirow{2}{*}{$\begin{array}{l}\text { No. of } \\
\text { items }\end{array}$} & \multicolumn{2}{|c|}{ Cronbach's $\alpha$} \\
\hline & & & & English & Russian \\
\hline Reading I & $\begin{array}{l}\text { Match word with appropriate } \\
\text { sentence }\end{array}$ & Definitions of words & 10 & .84 & .90 \\
\hline Reading 2 & Match notice with meaning & $\begin{array}{l}\text { Public notices and their } \\
\text { meanings }\end{array}$ & 9 & .80 & .83 \\
\hline Reading 3 & Match question with answer & $\begin{array}{l}\text { Interview from youth } \\
\text { magazine }\end{array}$ & 9 & .83 & .86 \\
\hline Reading 4 & Match question with answer & Quiz texts for teenagers & 8 & .85 & .85 \\
\hline
\end{tabular}

national educational standards of Hungary (for a detailed description of the test and its psychometric properties, see Csapó, 2014; Csapó \& Nikolov, 2009; Nikolov \& Szabó, 2015), they corresponded to the B1 level of the Common European Framework of Reference for Language (Council of Europe, 2001).

Two-way translators were involved in the translation of proficiency tests from English to Russian to guarantee the analogy assessment between English and Russian. Reading tests consisted of a comparable number of tasks and corresponded to the B1 level in both target languages (Table 1). Tasks focused on meaning (not form), and although texts were authentic, they were appropriate for individuals aged 14 to 18 years. Using multiple matrix booklet designs (Rutkowski et al., 2010), the structure of text items varied from a single word, an expression, or a sentence, to a very brief paragraph. All rubrics were provided in the foreign language. To facilitate student comprehension and to clarify the requirements of test instructions, samples of correctly completed items were included in the tests. Items in four achievement tests ranged between eight and 10; each language test comprised a total of 36 items. On average, each student worked on 18.37 reading items in English $(S D=8.96)$ and 16.15 reading items in Russian $(S D=10.35)$. The scaling of all achievement tests was based on a one-parameter logistic IRT model (Rasch model). Using the software ConQuest2.0 (Wu et al., 2007), weighted likelihood estimates (WLEs; Warm, 1989) were applied for the estimation of students' ability from the test items. The scaling of all achievement tests was based on a one-parameter logistic IRT model (Rasch model). The WLE reliabilities (Wu et al., 2007) were good for all reading achievement tests: English reading $=.88$; Russian reading $=.88$ (see also Tables 1 and 2 ).

Self-concept. Students' reading self-concepts were assessed by adapting an internationally validated questionnaire, the Self-Description Questionnaire-II (SDQ-II; Marsh, 1990) in the two target languages (English and Russian), which was translated by two-way translators in Azerbaijani. Although the questionnaire has been validated internationally (German: Arens et al., 2011; American: Bong, 1998; Chinese: Yang et al., 2014), the present study further provided discriminant validity of the internal structure (Table 3). The same set of items were used across two foreign 
Table 2. Descriptive Statistics.

\begin{tabular}{|c|c|c|c|c|c|c|c|c|c|c|}
\hline \multirow[b]{2}{*}{ Variables } & \multirow[b]{2}{*}{ Reliability } & \multirow[b]{2}{*}{$\alpha$} & \multicolumn{4}{|c|}{ Boys } & \multicolumn{4}{|c|}{ Girls } \\
\hline & & & $M$ & $S D$ & Skew & Kurtosis & $M$ & $S D$ & Skew & Kurtosis \\
\hline \multicolumn{11}{|l|}{ Reading self-concept } \\
\hline English cognitive & .93 & .93 & 3.65 & 1.17 & -0.75 & -0.25 & 3.63 & 1.10 & -0.62 & -0.66 \\
\hline English affective & .96 & .96 & 3.64 & 1.44 & -0.83 & -0.19 & 3.58 & 1.86 & -0.80 & -0.70 \\
\hline Russian cognitive & .93 & .93 & 3.09 & 1.77 & -0.11 & -1.27 & 2.77 & 1.52 & 0.25 & -0.96 \\
\hline Russian affective & .94 & .94 & 3.24 & 1.64 & -0.26 & -1.16 & 3.10 & 1.56 & 0.05 & -1.26 \\
\hline \multicolumn{11}{|l|}{ Achievement } \\
\hline English achievement & .88 & .93 & 0.51 & 0.06 & -0.13 & -0.83 & 0.52 & 0.06 & 0.08 & -0.99 \\
\hline Russian achievement & .88 & .95 & 0.46 & 0.08 & 0.10 & -1.27 & 0.44 & 0.08 & 0.23 & -1.15 \\
\hline
\end{tabular}

Note. The self-concept Ms and SDs indicate manifest aggregations of the items. $\alpha=$ Cronbach's alpha reliability coefficient; reliability = for self-concept: scale reliability ( $\rho$; Raykov, 2009) and for achievement: WLE reliability (Wu et al., 2007); WLE = weighted likelihood estimate.

Table 3. Standardized Correlations of Internal Structure for Model 8, Figure I (b).

\begin{tabular}{|c|c|c|c|c|c|c|c|c|c|c|c|c|}
\hline Items & I & 2 & 3 & 4 & 5 & 6 & 7 & 8 & 9 & 10 & II & 12 \\
\hline I. ESCI & 1.00 & & & & & & & & & & & \\
\hline 2. ESC2 & .84 & 1.00 & & & & & & & & & & \\
\hline 3. $\mathrm{ESC} 3$ & .81 & .81 & 1.00 & & & & & & & & & \\
\hline 4. ESAI & .68 & .66 & .62 & 1.00 & & & & & & & & \\
\hline 5. ESA2 & .66 & .67 & .63 & .89 & 1.00 & & & & & & & \\
\hline 6. ESA3 & .65 & .67 & .60 & .86 & .88 & 1.00 & & & & & & \\
\hline 7. RSCI & .10 & .07 & .07 & .12 & .11 & .14 & 1.00 & & & & & \\
\hline 8. RSC2 & .07 & .07 & .06 & .09 & .07 & .09 & .80 & 1.00 & & & & \\
\hline 9. RSC3 & .05 & .06 & .06 & .08 & .04 & .08 & .81 & .82 & 1.00 & & & \\
\hline 10. RSAI & .04 & .02 & -.04 & .09 & .06 & .08 & .72 & .66 & .72 & 1.00 & & \\
\hline II. RSA2 & .08 & .06 & .00 & .07 & .05 & .09 & .70 & .68 & .70 & .85 & 1.00 & \\
\hline 12. RSA3 & .07 & .07 & .04 & .11 & .09 & .13 & .70 & .64 & .67 & .83 & .82 & 1.00 \\
\hline
\end{tabular}

Note. Standardized correlations are significant at the .001 level (two-tailed). ESC $=$ English self-concept cognitive, ESA $=$ English self-concept affective, RSC $=$ Russian self-concept cognitive, RSA $=$ Russian self-concept affective.

languages to evaluate students' reading self-concepts in cognitive (e.g., I am good at reading (English); Study reading is easy for me (Russian)) and affective (e.g., I like reading texts (English); I enjoy reading texts (Russian)) domains (see also Table 4 for the item wordings and the descriptive statistics of the items.). The students were asked to think of one of the language domains when responding to the items. All scales (cognitive and affective scales in two language domains) consisted of three items to which students were asked to answer on a 5-point Likert-type scale (strongly disagree, disagree, neither agree nor disagree, agree, strongly agree). Higher values on the scales indicated higher levels of self-concept. All scales used in the present study showed good to excellent reliability estimates regarding coefficient alpha $(\alpha)$ and likewise scale reliability $(\rho)$ index of a structural equation model (SEM; Raykov, 2009; see Table 2). 
Table 4. Means, Standard Deviations, and Uniquenesses of Each Item for Model 7, Figure I(b).

\begin{tabular}{lccc}
\hline Items & $M$ & SD & Uniquenesses** \\
\hline I. Study English reading is easy for me (ESCI). & $3.6 \mathrm{I}$ & 1.33 & .220 \\
2. I am good at English reading (ESC2). & 3.66 & 1.26 & .194 \\
3. I learn English reading quickly (ESC3). & 3.58 & 1.43 & .317 \\
4. I like reading English texts (ESAI). & 3.95 & $1.8 \mathrm{I}$ & .212 \\
5. I enjoy reading English texts (ESA2). & 3.82 & 1.92 & .186 \\
6. I am interested in English reading texts (ESA3). & 3.52 & 1.90 & .288 \\
7. Study Russian reading is easy for me (RSCI). & 2.94 & 2.07 & .402 \\
8. I am good at Russian reading (RSC2). & 2.92 & 1.81 & .373 \\
9. I learn Russian reading quickly (RSC3). & 2.96 & 1.98 & .347 \\
I0. I like reading Russian texts (RSAI). & 3.16 & 1.83 & .252 \\
II. I enjoy reading Russian texts (RSA2). & 3.07 & 1.76 & $.28 \mathrm{I}$ \\
I2. I am interested in Russian reading texts (RSA3). & 3.19 & 1.83 & .374 \\
\hline
\end{tabular}

Note. The uniquenesses of each item is the residual variance. ESC = English self-concept cognitive, $\mathrm{ESA}=$ English self-concept affective, $\mathrm{RSC}=$ Russian self-concept cognitive, $\mathrm{RSA}=$ Russian self-concept affective.

$* * p<.001$.

\section{Statistical Analysis}

Model estimation. The present study estimated sets of models within the SEM framework using Mplus 7.31 (Muthén \& Muthén, 1998-2015). As there are some slight deviation from normality assumptions (skewness of achievement test scores range from -0.13 to 0.23 ; skewness of self-concept items range from -0.82 to 0.25 ; kurtosis of achievement test scores range from -1.27 to -0.83 ; kurtosis of selfconcept items range from -1.27 to -0.19 ; Table 2 ), this study selected the default (maximum likelihood) estimator that has been found adequate for treating response scales with five categories as continuous variables (Wang \& Wang, 2020). Furthermore, studies (e.g., Marsh \& Hau, 1996) recommended the usage of correlated uniquenesses for parallel worded items. As the same item ( $I$ am good in reading (English/Russian)) was used for multiple domains in this study, correlated uniquenesses were applied to prevent biased parameter estimates that could lead to inflated correlations among corresponding latent factors across different domains. As missing data were small (2.6\% for reading self-concept responses), full information maximum likelihood (FIML) estimation was used to treat missing data, which has been recognized to be a reliable and efficient procedure that results in unbiased estimates (Enders, 2010).

First, the separation of cognitive and affective components of reading self-concept was examined in two domains of English and Russian, separately. The first set of models comprised measurement models for examining the multidimensionality of reading self-concepts by comparing unidimensional and multidimensional models. 
Table 5. Goodness-of-Fit Indices.

\begin{tabular}{|c|c|c|c|c|c|c|c|}
\hline No. & Model description & $\chi^{2}$ & $d f$ & $\mathrm{CFI}$ & TLI & RMSEA & SRMR \\
\hline ' & Unidimensional self-concept for English & 419.047 & 9 & .814 & 689 & .361 & .092 \\
\hline 2 & Unidimensional self-concept for Russian & 231.546 & 9 & .890 & .816 & .266 & .050 \\
\hline 3 & Two-factor model for English & 13.000 & 8 & .998 & .996 & .042 & .008 \\
\hline 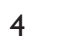 & Two-factor model for Russian & 13.134 & 8 & .997 & .995 & .043 & .011 \\
\hline 5 & $\begin{array}{l}\text { Two-factor model for English + reading } \\
\text { achievement test }\end{array}$ & 19.5 & 12 & .997 & .994 & .043 & .010 \\
\hline 6 & $\begin{array}{l}\text { Two-factor model for Russian }+ \text { reading } \\
\text { achievement test }\end{array}$ & 19.318 & 12 & .996 & .994 & .042 & .013 \\
\hline 7 & Four-factor model for English and Russian & 66.257 & 42 & .994 & .991 & .041 & .019 \\
\hline 8 & $\begin{array}{l}\text { Four-factor model for English and Russian } \\
+ \text { reading achievement tests }\end{array}$ & 94.938 & 58 & .992 & .987 & .043 & .019 \\
\hline 9 & Conflated model for English and Russian & 759.824 & 67 & .844 & .788 & .172 & .058 \\
\hline
\end{tabular}

Note. CFI = comparative fit index; TLI = Tucker-Lewis index; RMSEA = root mean square of approximation; SRMR = standardized root mean squared residual.

In unidimensional models (Models 1-2 in Table 5), the items relating to cognitive and affective components of self-concept were assessed in this study from one common first-order factor. The multidimensional models (Models 3-4) assume separate first-order factors for each component of reading self-concept. Therefore, two firstorder factors are assumed in these models constituting cognitive and affective components.

Furthermore, achievement test scores were incorporated in the models. Students' achievements in the English and Russian reading domains were added to two-factor multidimensional models (Models 3-4) resulting in Models 5 and 6 to test differential relations between cognitive and affective self-concepts and achievement measures. The next series of models (Models 7-8) were the structural models that tested the $\mathrm{I} / \mathrm{E}$ frame of reference within foreign language domains. To examine this assumption, first-order factors of cognitive and affective components of reading self-concepts in two target languages were included (Model 7). Subsequently, achievement measures were added to examine whether the two components of reading self-concepts in English and Russian indicate differential relations to achievement (Model 8).

To test whether the twofold multidimensional structure of reading self-concept was invariant across gender, the multigroup analysis was performed. To examine the invariance of twofold multidimensional models (Tables 6-7), this study followed the propositions of Sass and Schmitt (2013) by starting with tests of configural invariance in which only the same factor structure was assumed across groups. All model parameters were freely estimated. Subsequently, this model was important as a baseline model for more restrictive models that can be compared and tested with increasingly more restrictions. In the next step, setting all first-order factor loadings to be equal 
Table 6. Goodness-of-Fit Indices of Measurement Invariance Across Gender for Model 7.

\begin{tabular}{llcccccccc}
\hline Invariance steps & Gender & $\chi^{2}$ contribution & $\chi^{2}$ & df & $p$ & CFI & TLI & RMSEA & SRMR \\
\hline Configural invariance & Boys & 80.907 & & & & & & & \\
& Girls & 47.019 & 127.926 & 84 & .001 & .990 & .984 & .055 & .026 \\
Metric invariance & Boys & 84.241 & & & & & & & \\
& Girls & 48.829 & 133.070 & 92 & .003 & .990 & .986 & .051 & .029 \\
Scalar invariance & Boys & 86.677 & & & & & & & \\
& Girls & 50.589 & 137.266 & 100 & .008 & .991 & .988 & .046 & .030 \\
\hline
\end{tabular}

Note. CFI = confirmatory fit index; TLI = Tucker-Lewis index; RMSEA = root mean square error of approximation; $\mathrm{SRMR}=$ standardized root mean square residual.

Table 7. Goodness-of-Fit Indices of Measurement Invariance Across Gender for Model 8.

\begin{tabular}{|c|c|c|c|c|c|c|c|c|c|}
\hline Invariance steps & Gender & $\chi^{2}$ contribution & $\chi^{2}$ & $p$ & $D f$ & $\mathrm{CFI}$ & TLI & RMSEA & SRMR \\
\hline \multirow[t]{2}{*}{ Configural invariance } & Boys & 101.937 & & & & & & & \\
\hline & Girls & 72.452 & 174.389 & .0004 & 116 & .987 & .979 & .054 & .026 \\
\hline \multirow[t]{2}{*}{ Metric invariance } & Boys & 105.472 & & & & & & & \\
\hline & Girls & 74.456 & 179.928 & .0003 & 124 & .987 & .982 & .051 & .029 \\
\hline \multirow[t]{2}{*}{ Scalar invariance } & Boys & 111.452 & & & & & & & \\
\hline & Girls & 79.625 & 191.076 & .0013 & 136 & .988 & .983 & .048 & .040 \\
\hline \multirow{2}{*}{$\begin{array}{r}\text { Strict (factor } \\
\text { invariance) }\end{array}$} & Boys & 117.733 & & & & & & & \\
\hline & Girls & 97.195 & 214.927 & .0001 & 143 & .984 & .979 & .054 & .082 \\
\hline
\end{tabular}

Note. CFI = confirmatory fit index; TLI = Tucker-Lewis index; RMSEA = root mean square error of approximation; SRMR $=$ standardized root mean square residual.

across groups, metric invariance was performed, which was the precondition of all further invariance tests (Millsap, 2011). In subsequent models, this study tested whether boys and girls display differences in the separation of cognitive and affective reading self-concept factors fixing the factor loadings to be equivalent across gender and allowing the item intercepts to vary freely. After metric and scalar invariances were obtained, strict factorial invariance was performed setting the variable's residuals equal across the groups.

Evaluation of model fit. As the chi-square statistic represents variation between the assumed model and the observed sample covariance matrices, it was used to assess the goodness-of-fit of models performed within the SEM framework. However, being sensitive to sample size, the chi-square statistic frequently generates significant values resulting in model rejection (Marsh et al., 2005). Thus, the authors applied the most commonly used descriptive goodness-of-fit indices such as the comparative fit index (CFI), the Tucker-Lewis index (TLI), the root mean square error of approximation (RMSEA), and the standardized root mean square residual (SRMR). Hu and Bentler (1999) suggested the strict cut-off value of .95 as a criterion for CFI and TLI, which is considered an adequate model fit. For interpretation of RMSEA, Browne and Cudeck 
(1993) recommended values about .05 indicate "close fit" and values near .08 indicate "fair fit." Hu and Bentler (1995) considered values below .05 as a good model fit for SRMR. However, Kline (2005) suggested values close to .08 as a good model fit. The vast amount of literature on the SEM framework has provided the controversial cut-off values for various goodness-of-fit indices. Subsequently, to abstain from subjective interpretation and to retain theoretical adequacy of the model and statistical compliance, the authors considered the results of various fit indices concurrently.

The purpose of this study involved the examination of nested models. Specifying a subtype of a more general model, models were nested within each other. Thus, fixed model parameters in the nested model were freely estimated in the more general model. The comparison of the nested model was performed to test whether the twofold structure of reading self-concepts in two foreign languages was invariant across gender and to examine whether the I/E model assumption within the foreign language domain was applicable across gender. As chi-square was sensitive to sample size, researchers (Marsh et al., 2005) suggested various goodness-of-fit indices for the examination and comparison of nested models. Chen (2007) introduced that invariance can be assumed when the value of CFI did not decrease more than .01, and RMSEA did not increase more than .015 among less and more restrictive models. Thus, this study used the chi-square value and Hu and Bentler's (1995) suggested cutoff values for CFI, TLI, RMSEA, and SRMR as goodness-of-fit indices to assess model fit.

\section{Results}

\section{Structure of Reading Self-Concepts}

The two-factor models (Models 3-4 in Table 5) and the four-factor model (Model 7), which assumed distinct factors for the two components (cognitive and affective) of reading self-concept, resulted in good levels of fit to the data. Conversely, the models that stated a unidimensional factor for two components of reading self-concept (Models 1-2) did not demonstrate adequate fit to the data. From the substantial and positive factor loadings (Figure 1(a)), it was clear that two components of reading selfconcept were well defined in two foreign languages. Figure 1(a) displays the standardized correlations between cognitive and affective factors resulting from the two-factor models. The relationships among the two-component self-concept factors were substantial, thus providing evidence for the students' ability to distinguish between selfconcepts related to cognitive and affective components, indicating twofold multidimensionality within reading self-concept. In this respect, it was necessary to indicate that the two components of reading self-concept were found to be more interrelated within Russian $(r=.84)$ as the second foreign language compared with English as students' first foreign language ( $r=.77)$. These findings support the assumption of the existence of multidimensionality within reading self-concepts of different foreign languages. 


\section{Reading Self-Concepts}

a

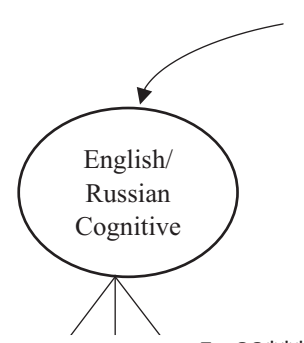

E: $.91^{* * *}$

R: $.89 * * *$

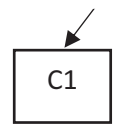

E: . $92 * * *$

E: $.88^{* * *}$

R: . $89 * * *$

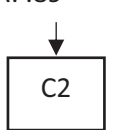

R: . $91^{* * *}$

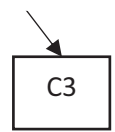

E: $.77^{* * *}$

R: $.84^{* * *}$
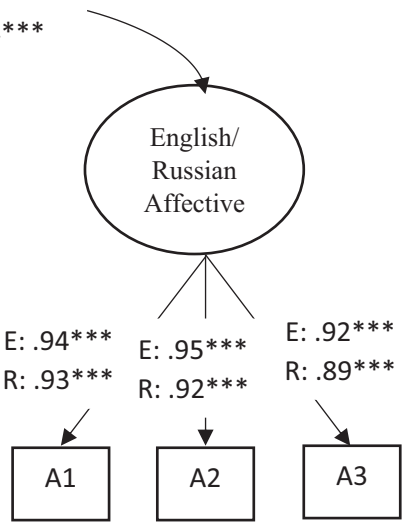

E: .95*

R: $.92 * * *$

b

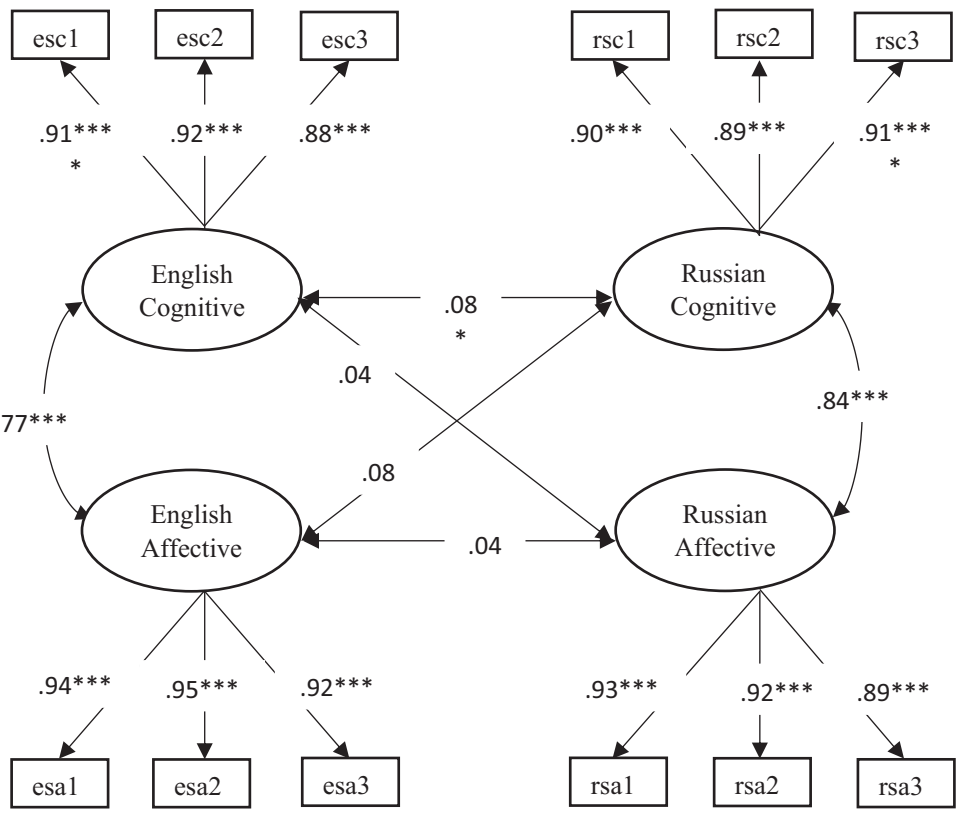

Figure I. (continued) 


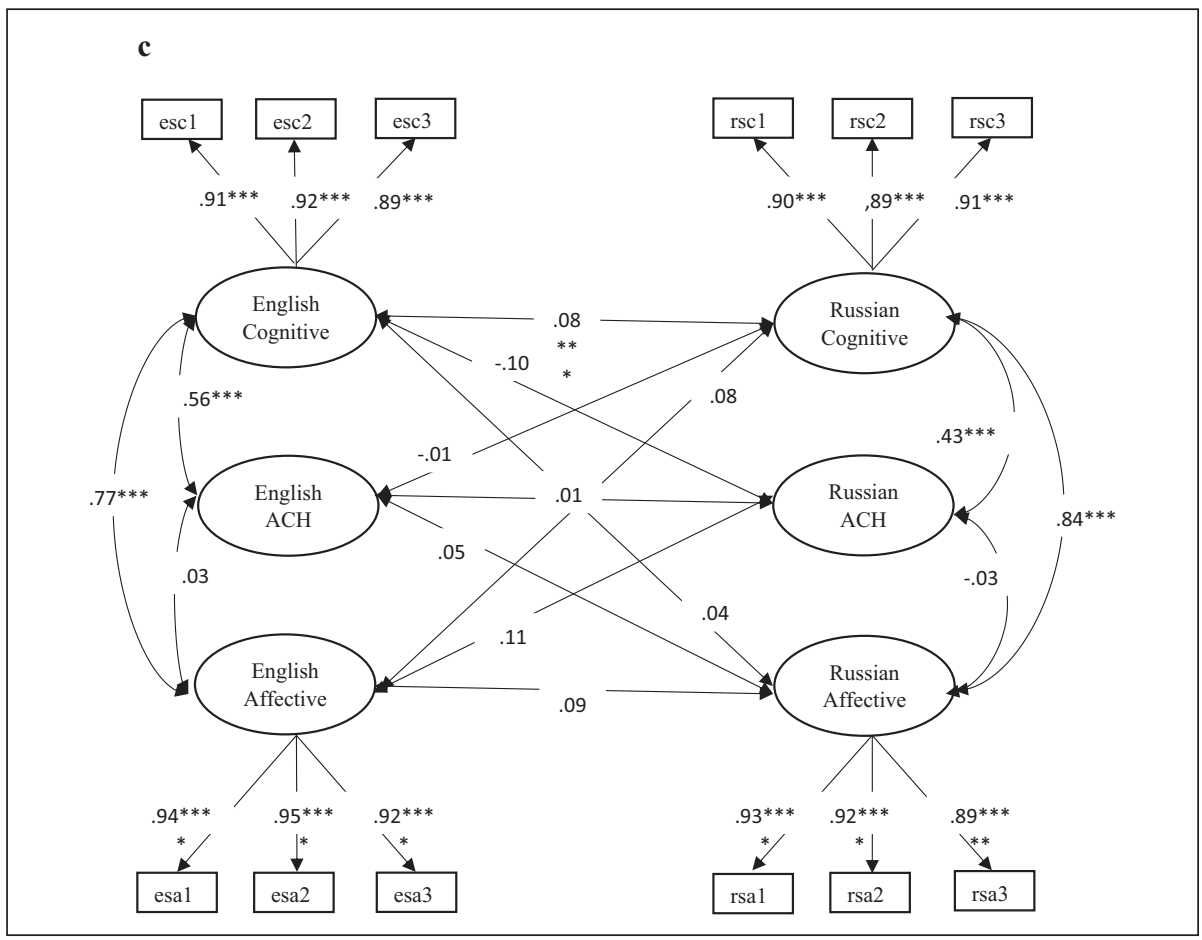

Figure I. (a) Two-factor model for English and Russia; (b) Four-factor model for English and Russian; (c) Four-factor model for English and Russian with achievement scores. Confirmatory factor analysis results among the latent factors of cognitive and affective reading self-concepts of English and Russian, reading achievement of two target languages, and the loadings of their indicators (all parameters are standardized).

Note. Correlations among uniquenesses of parallel worded items are not shown (Table 5, Models 3-4; 9-10; see also item-correlated uniqueness in Table 4). E = English; R = Russian; esc = English cognitive self-concept, esa $=$ English affective self-concept, $r s c=$ Russian cognitive self-concept, $r s a=$ Russian affective self-concept; $\mathrm{ACH}=$ achievement.

Values are significant at $* * * p<.001$.

\section{Relations to Achievement}

To further examine the notion of multidimensionality, this study considered relations between two-factor models of reading self-concept and reading achievement (Models 5-6 in Table 5). Students' achievement scores were found to be dissimilarly related to the two-factor models for English (cognitive: $r=.56$, affective: $r=.03$ ) and Russian (cognitive: $r=.42$, affective: $r=.01$ ). Cognitive components of reading self-concepts in both foreign languages demonstrated strong, significant relationships with reading achievement, whereas there was a weak, nonsignificant correlation between affective components and reading achievements. It was interesting to note that the cognitive component was more strongly related to reading achievement in the English domain than Russian, indicating a reasonable difference between foreign languages. 
Table 8. Latent Factor Correlations Between Achievement and Self-Concept (Models 8-9 in Table 5).

\begin{tabular}{|c|c|c|c|c|c|c|}
\hline \multirow[b]{2}{*}{ Variables } & \multicolumn{2}{|c|}{ Conflated model } & \multicolumn{4}{|c|}{ Separated model } \\
\hline & Eng RSC & Rus RSC & $\begin{array}{l}\text { Eng RSC } \\
\text { cognitive }\end{array}$ & $\begin{array}{l}\text { Eng RSC } \\
\text { affective }\end{array}$ & $\begin{array}{l}\text { Rus RSC } \\
\text { cognitive }\end{array}$ & $\begin{array}{l}\text { Rus RSC } \\
\text { affective }\end{array}$ \\
\hline Eng RACH & $0.51 * *$ & 0.03 & $.56 * *$ & .03 & -.01 & .05 \\
\hline Rus RACH & 0.02 & $0.39 * *$ & -.10 & .11 & $.43^{* *}$ & -.03 \\
\hline Eng RSC & 1.00 & 0.09 & - & - & - & \\
\hline Rus RSC & 0.09 & 1.00 & - & - & - & \\
\hline
\end{tabular}

Note. $\mathrm{RSC}=$ reading self-concept; Eng $=$ English; $\mathrm{RACH}=$ reading achievement; Rus $=$ Russian. $* * p<.001$.

Furthermore, when achievement test scores were integrated into the two-factor models, they showed a slight decline in a model fit in both English (Model 5: $\Delta \chi^{2}=$ $+.6587 ; \Delta$ CFI $=-.001 ; \Delta$ TLI $=-.002$; RMSEA $=+.001 ;$ SRMR $=+.002)$ and Russian $\left(\Delta \chi^{2}=+.6184 ; \Delta \mathrm{CFI}=-.001 ; \Delta \mathrm{TLI}=-.001 ; \Delta \mathrm{RMSEA}=-.001\right.$ [a slight increase]; $\triangle \mathrm{SRMR}=+.002)$.

Next, this study investigated the internal structure of reading self-concept assessing the relationships between cognitive and affective components of foreign languages in a single model (Model 8). From the substantial factor loadings (Figure 1(b)) and significant goodness-of-fit indices, it was clear that the four-factor model (Model 8) showed a good fit to the data. Correlations between cognitive and affective components of the corresponding domains of foreign language were high, positive, and significant (English: $r=.77$; Russian: $r=.84$; see Figure 1(b)), whereas there were nonsignificant, near-zero correlations between corresponding domains of cognitive self-concept $(r=.08, n s)$ and affective self-concept $(r=.04, n s)$ as well as the correlations between noncorresponding domains of cognitive and affective self-concepts (English cognitive and Russian affective: $r=.04, n s$; Russian cognitive and English affective: $r=.08$ ). In the subsequent model (Model 8 in Table 5), the present study examined the relations of first-order factors of cognitive and affective components of reading self-concepts with reading achievements in a single model. Although Model 8 exhibited a good fit to the data, it also showed a slight decline compared with Model $7\left(\Delta \chi^{2}=+28.681 ; \Delta \mathrm{CFI}=-.002 ; \Delta \mathrm{TLI}=-.004 ;\right.$ RMSEA $\left.=+.002\right)$. Furthermore, this study examined the conflated model (Model 9) of reading self-concepts to reveal correlations between cognitive and affective components of reading self-concepts and reading achievements. Model 9 involved all six cognitive and affective items, which were expected to load in a single English and Russian domain and reading achievement test scores, and showed a poor fit to the data. Examining corresponding relations between conflated and separated models in two foreign languages (Table 8), this study found a reasonable difference (English conflated: $r=.51$, separated: the relationship between cognitive and achievement: $r=.56$; Russian conflated: $r=.39$, separated: the relationship between cognitive and achievement: $r=.43$ ) between two models. 
Thus, the models that implied separation between cognitive and affective components showed higher relationships between matching domains of cognitive and achievement domains than the relationships between achievement and conflated models that combined cognitive and affective components. As this study expected that students' ability levels would correlate with achievement, cognitive components of reading self-concepts showed high, significant correlations with reading achievements in two foreign languages, but there were near-zero and nonsignificant correlations between affective components of reading self-concepts and reading achievements (English: $r=.03, n s$; Russian: $r=.05, n s)$. Consequently, from the nonsignificant correlation indicators, it is clear that students perceive two foreign languages distinctly.

Gender invariance. Gender invariance was examined to investigate the separation of cognitive and affective components of reading self-concepts and their relations across gender. A set of measurement invariance models were performed. First, this study examined measurement invariance across gender for Model 7 (Table 5). The $p$ values of the chi-square tests for all invariance models were statistically significant, indicating the availability of the four-factor structure of reading self-concepts in two foreign languages for each gender (Table 6). The next step of the analysis was to test the extent to which the twofold multidimensional structure of reading self-concept within the foreign language domain and its relation were invariant across gender (Table 9). As all $p$ values of the chi-square tests for all invariance models were statistically significant, Model 8 showed conformity with each gender. Following the guidelines of researchers (Chen et al., 2005; Millsap, 2011), first this study tested the model of configural invariance of Model 8 (Table 5), assuming that boys and girls held the same structure of reading self-concept.

To test the configural invariance of the Model 8, all factor loadings and item intercepts were freed to vary for each group. This model resulted in inadequate levels of fit for each gender so that they were found to similarly demonstrate the twofold multidimensional structure and the $\mathrm{I} / \mathrm{E}$ frame of reference within reading self-concepts of English and Russian. The next step of measurement invariance was to test metric invariance whether the factor loadings were equivalent across gender, allowing the item intercepts to vary freely. The goodness-of-fit indices of the metric model of measurement invariance demonstrated a good fit to the data, indicating the nonexistence of item bias between gender. Fixing item intercepts to be equal across each gender group, the goodness-of-fit indices of the scalar invariance model also indicated a good fit to the data. The next step of measurement invariance was strict factorial invariance, which depicts the overall error in the prediction of the target construct. From the significant goodness-of-fit indices of the strict invariance model, it was clear that the observed variable's residuals were equal across the groups. Correlations among cognitive and affective self-concepts with achievements in the reading domain of English and Russian were not invariant across gender (Table 9). Although correlations between cognitive and affective components of reading self-concepts in English and Russian were similar across gender (English: boys: $r=.79$, girls: $r=.73$; Russian: boys: $r=$ .84 , girls: $r=.84$; see Table 9), boys and girls demonstrated differences in the 
Table 9. Standardized Latent Correlations of Configural Invariance for Boys and Girls.

\begin{tabular}{|c|c|c|c|c|c|}
\hline Variables & I & 2 & 3 & 4 & 5 \\
\hline \multicolumn{6}{|l|}{ I. English RSC cognitive } \\
\hline 2. English RSC affective & $.787^{* * *}(.730)$ & & & & \\
\hline 3. Russian RSC cognitive & $.056(.091)$ & $.138(.091)$ & & & \\
\hline 4. Russian RSC affective & $.014(.047)$ & $.132(.017)$ & $.842^{* * *}(.838)$ & & \\
\hline 5. English reading achievement & $.340 * *(.795)$ & $.181(-.098)$ & $-.072(.066)$ & $.181(.003)$ & \\
\hline 6. Russian reading achievement & $-.153(-.089)$ & $-.133(.132)$ & $.392^{* *}(.496)$ & $-.038(-.042)$ & $-.001(.053)$ \\
\hline
\end{tabular}

Note. The values for girls are in the parenthesis. RSC $=$ reading self-concept.

Values are significant at level ${ }^{* *} p<.01 . *^{* *} p<.001$.

relationships between cognitive components of reading self-concepts and reading achievements. Girls showed strong relations between cognitive components, which implied students' ability levels, and reading achievements compared with boys in both foreign languages (English: boys: $r=.34$, girls: $r=.80$; Russian: boys: $r=.39$, girls: $r=.50$ ). Furthermore, there were differences between two foreign language correlations, indicating stronger correlations between the cognitive component of reading self-concept and achievement in the English domain than in Russian.

Therefore, the results confirmed the separation of cognitive and affective components of reading self-concepts in English and Russian. Students perceived these two components separately in the reading domain. The findings also showed that there was no significant relationship between reading self-concept in two foreign languages, indicating that students had various perceptions toward reading in English and Russian. If a student had a lower self-concept or achievement in reading in one foreign language, it would not affect another foreign language reading self-concept and reading achievement. Moreover, the results indicated a stronger relationship between the cognitive component, which implied students' ability levels, in the corresponding domain with achievement than the affective component, which implied students' attitudes toward that domain. The findings of gender invariance showed that boys and girls did not differ in the structure of reading self-concept, but girls had higher reading selfconcepts if they performed well in the corresponding domain than boys.

\section{Discussion}

Research on twofold multidimensional self-concept has focused on the separability of cognitive and affective components of academic self-concept (Abu-Hilal et al., 2013; Arens et al., 2011; Yang et al., 2014) and its distinction for specific subjects (e.g., native language, mathematics). The present study aimed to examine cognitive and affective components of reading self-concept within the foreign language domain (English and Russian) and to test the applicability of the I/E frame of reference model to English and Russian domains studying the internal structure of the foreign language domain. In addition, this study aimed to test gender invariance, or whether boys and girls would hold the same twofold multidimensional structure of reading self-concept in two foreign languages. 
The results of this study support the twofold multidimensional structure of reading self-concept in English as students' first foreign language and in Russian as students' second foreign language, as well as the applicability of the $\mathrm{I} / \mathrm{E}$ frame of reference model within the foreign language domain. Evidence of the twofold multidimensional structure within reading self-concepts of foreign languages was provided because the models differentiating between cognitive and affective components of self-concept fitted the data substantially better than unidimensional models. Cognitive and affective components of reading self-concept were found to show high but not perfect relations to one another, further supporting their distinctiveness. Evidence of the applicability of the $\mathrm{I} / \mathrm{E}$ frame of reference model to the foreign language domain was provided as the four-factor model referring to separated cognitive and affective components of reading self-concepts in English and Russian showed a better fit to the data than a conflated model that was found to demonstrate near-zero, nonsignificant correlations between two foreign languages, indicating distinctive reading self-concept for each language.

This study is in alignment with Yeung and Wong's (2004) study that founded distinctive verbal self-concepts for three languages, indicating the multidimensional structure of self-concept within the verbal domain. Furthermore, this study is also consistent with Abu-Hilal et al.'s (2013) research that studied a twofold multidimensional structure of self-concept within mathematics and science domains. This notion was further supported by the consideration of achievement relations and gender differences as further methodological approaches to examine the structure of reading selfconcepts within the foreign language domain. Although the findings appeared to be similar across the two target languages, subtle differences were manifested.

\section{Extension of the I/E Model to Foreign Languages}

To further substantiate twofold multidimensionality, this study inspected the internal structure of reading self-concept of foreign languages and found that the four-factor model with incorporated achievement tests fitted the data considerably better than conflated models. As there was a shortage in studies investigating the internal structure of reading self-concepts of the foreign language domain, this result contributes to domain-specificity of self-concept research, reading comprehension, and foreign language learning and teaching. Furthermore, investigating the internal structure of reading self-concept, the present study found different relations between achievements and two components of reading self-concept.

Cognitive components, which implied students' ability levels, related highly to achievements in the corresponding domains compared with affective components, which implied students' attitudes. These findings are consistent with Abu-Hilal et al.'s (2013) study that revealed high correlations between cognitive components of selfconcept and achievement within mathematics $(r=.58)$ and science $(r=.57)$ domains and Arens et al.'s (2011) study that found high correlations between cognitive selfconcepts and achievements within German $(r=.63)$ and mathematics $(r=.61)$ domains. Moreover, the results of the high relations between cognitive and affective 
components of reading self-concept within two foreign languages correspond to the findings of Arens et al.'s (2011) study that found high correlations between cognitive and affective components within mathematics $(r=.81)$ and German $(r=.78)$ domains and Abu-Hilal et al.'s (2013) study that found high correlations within science $(r=$ $.74)$ and mathematics $(r=.74)$ domains.

These results support and contribute to the multidimensionality of domain-specific self-concepts and the extension of the classic I/E model to the foreign language domain. However, this study further found a near-zero, nonsignificant relationship between the cognitive components of reading self-concepts in two foreign languages and between affective components of reading self-concepts in two foreign languages. Nonsignificant correlations were also revealed between cognitive and affective components of noncorresponding domains. These results were not in line with previous studies (e.g., Abu-Hilal et al., 2013; Arens et al., 2011) that found negligible but significant correlations between corresponding and noncorresponding domains of cognitive and affective self-concepts, indicating the distinction of reading self-concepts in two foreign languages. These findings suggest that students' cognitive and affective self-concepts are domain-specific, which matches with Marsh and Yeung's (1998) study showing distinctiveness of cognitive and affective reading self-concepts in two foreign languages and hence extended the I/E model assumption to the construct of the foreign language reading domain. The results of this study showed that although cognitive and affective components were distinctive, there were high correlations between corresponding domains of cognitive and affective components in English $(r=.77)$ and Russian $(r=.84)$, but nonsignificant, near-zero correlations between noncorresponding domains, which were in line with the I/E model (Marsh et al., 1998).

Furthermore, in a meta-analysis of 69 data sets $(N=125,308)$, Möller et al. (2009) found high correlations between mathematics and verbal achievements $(r=.67)$, but near-zero correlations between verbal and mathematics self-concepts $(r=.10)$. Although this study found nonsignificant, near-zero correlations between reading selfconcepts in two foreign languages, there were nonsignificant, near-zero correlations between reading achievements in English and Russian. The results of the I/E model within the reading domain in two foreign languages did not support the I/E model of academic self-concept.

\section{Gender Invariance and Generalizability Across Languages}

Support for the twofold multidimensional structure of self-concept emerges from the previous studies that have examined gender invariance among subject-specific selfconcepts (Abu-Hilal et al., 2013; Arens et al., 2011). Consistent with past research (Abu-Hilal, 2005; Arens \& Jansen, 2016; Irwing, 1996; Marsh, 1989), boys and girls were found to develop a similar structure of reading self-concept in two foreign languages. However, there was a difference between boys and girls regarding correlations between cognitive and affective components of reading self-concept with reading achievement in English and Russian. Girls were found to display 
higher correlations between cognitive self-concepts and achievements in two foreign languages than boys. This result corresponds to Abu-Hilal et al.'s (2013) study that found higher relations between cognitive self-concept and achievement in the reading domain for girls (mathematics: $r=.63$; science: $r=.63$ ) than boys (mathematics: $r$ $=.53$; science: $r=.45$ ).

As the self-concept construct is hypothetical and multidimensional, it is worthwhile to be validated by using a construct validity approach. The measurement invariance of factor structure across boys and girls implies equal validity of given indicator measures to the same component of reading self-concept for each gender. This study inspected measurement invariance across gender for the four-factor model. Next, achievement tests were included for examining the invariance of correlations between two components and achievements across gender. All models of measurement invariance showed a good fit to the data, indicating the availability of the multidimensional structure of self-concept within the reading domain and extension of the I/E model to reading self-concept for each gender. The findings of the present study are in line with Marsh's (1993) study.

At first sight, the results of multidimensional reading self-concept structures in two foreign languages were implied to be consistent across two target languages. The close inspection of English and Russian reading self-concepts reveals some differences between the findings for English as a first foreign language and Russian as a second foreign language. The cognitive and affective components related to English were found to be less interrelated than those for Russian, suggesting that students might be less likely to differentiate two components of reading self-concept for English. The results were indicating differences between languages complied with previous findings (Arens \& Jansen, 2016). Examining the relations between reading achievement test scores and cognitive components of reading self-concepts of two foreign languages, this study found a subtle difference between English and Russian. However, the inspection of the correlations between these achievement test scores and cognitive components of reading self-concepts in English and Russian across gender indicates that reading achievement was more highly correlated to cognitive self-concept in the Russian domain than in English, which was consistent with Arens and Jansen's (2016) study that found a higher correlation between reading achievement and reading self-concept within the French domain $(r=.52)$ than in English $(r$ $=.47$ ). Having these results, it is clear that other factors influence perceptions of reading skills of foreign languages. Teaching methods could be one of those factors, which is subject to future examination.

\section{Limitations, Future Research, and Practical Implications}

The findings of this study suggest that although there are some differences between the two foreign languages, findings contribute to the multifaceted and domain-specific self-concept research. The present study might be conducive to self-concept research and theory regarding further empirical support for the operation of twofold multidimensionality and the I/E model of self-concept within a domain-specific level. 
Regardless of the substantial findings of this study, future research is essential to investigate further twofold multidimensionality and the I/E model within the domainspecific level. Although the contribution of the present study to twofold multidimensionality and the I/E model is noteworthy, several limitations should be addressed. First, the present study is cross-sectional and targeted only 10th-grade Azeri students. Longitudinal studies are undoubtedly necessary to gain an accurate and deep intuitive understanding of the operation of the twofold multidimensionality and the I/E model of the reading self-concept structure within the foreign language domain. As studies (e.g., Marsh \& Ayotte, 2003) explored the differentiation of self-concept according to the students' age, it might be beneficial to compare the twofold multidimensional structure and the I/E model of reading self-concept within the foreign language domain between younger and older students. Moreover, longitudinal studies allow the investigation of the interrelation across time, as they enable the examination of self-concept and achievement relations that have been explored to be reciprocal (Marsh \& Craven, 2006).

Second, to gain insight into the development of the twofold multidimensional structure and the I/E frame of reference model of reading self-concept within the foreign language domain, future studies can integrate the five paradoxical frame of reference (social comparison theory and frame of reference, dimensional comparison theory, cross-cultural self-concept paradox, and big-fish-little-pond effect) and contextual effects in reading self-concept formation that occur at different levels, as research has found psychological comparison processes influence self-perceptions and their relations to distal outcomes (see Marsh et al., 2020). Irrespective of the findings of this study that suggested the generalizability of the twofold multidimensional structure across the reading self-concepts related to students' English as a first foreign language and Russian as a second foreign language, a closer inspection found subtle differences between the structures of two foreign languages. This inspection might serve as a basis for further studies on similarities and differences in reading self-concepts of two foreign languages.

It might be interesting to examine the applicability of the given conceptions to other domains such as listening, writing, and speaking. For example, the twofold multidimensional structure and the $\mathrm{I} / \mathrm{E}$ frame of reference model of self-concept related to cognitive and affective components could be examined. This assumption would also allow for clarification of further multidimensionality within domain-specific self-concepts and to what extent this is theoretically and practically relevant. Therefore, researchers could examine the relationships of more domain-specific self-concepts with achievements of corresponding domains within different foreign languages.

Regarding further research on reading self-concept within the foreign language domain, it might also be beneficial to examine twofold multidimensionality of domainspecific and skill-related differentiation of motivational constructs such as self-efficacy. Although the construct of self-efficacy was found to be closely related to self-concept, which meant both constructs relate to students' perceptions of ability, most studies (Bong \& Skaalvik, 2003; Jansen et al., 2015; Parker et al., 2014) found theoretical and empirical separation between self-concept and self-efficacy. While 
self-concept applies to students' self-perceptions of their ability related to a given domain in general and is past-oriented, self-efficacy refers to students' expectations and confidence to perform a specific task successfully and is future-oriented. As Arens and Jansen (2016) indicated that self-concept and self-efficacy became more difficult to distinguish when both constructs were applied to a more specific content domain; that task-orientation was considered as an essential part of the conceptualization of self-efficacy was partially confused with the specificity level of the item. The selfconcept items used in the current study were conceptually distinct from the items of self-efficacy, such as item example used by Pajares et al. (1999) to assess writing: "How sure are you that you can correctly spell all words in a one-page story or composition?" (as cited in Arens \& Jansen, 2016, p. 660). Hence, the empirical distinction of self-concept and self-efficacy on the level of specific domains would be compelling to explore in future studies.

The findings have significant practical implications for the design of interventions to improve students' foreign language self-concept and achievement. Educators need to have a clear understanding of how cognitive and affective components of reading self-concepts in two foreign languages operate to improve students' reading skills. General perceptions of instructors about domain-specific academic competencies are noncompliant with learners' perceptions, indicating that students' competencies in different domains are grounded on external assessment, and do not differ between and within domains (Marsh \& Craven, 1997). Teachers are likely to assume that if students have a positive attitude toward reading, they will also have a positive belief about their ability and show better performance. Educators may also hold the belief that if students have a high self-concept in one foreign language, they will have a high selfconcept in another foreign language (Yeung \& Wong, 2004). Therefore, the findings of this study suggest that students hold distinct reading self-concepts for each foreign language. Students' reading self-concept in English will not be affected by reading self-concept in Russian.

Similarly, if students perform well in English reading, these students' reading selfconcepts in Russian will not be influenced by English achievement. If students hold low beliefs related to their competence in a domain in which they show weak performance, teachers should intervene to support students' learning by improving and strengthening their beliefs about their abilities in a given domain. The findings of this study are likewise worthwhile to curriculum developers, mainly in the foreign language field, to develop proper strategies to foster the growth of students' beliefs about their reading ability. As the affective component is highly related to the cognitive component of reading self-concept, which is highly related to achievement, and if educators want to emphasize the importance of reading, they need to work on the affective component of reading self-concept of a foreign language in addition to the cognitive component.

\section{Declaration of Conflicting Interests}

The authors declared no potential conflicts of interest with respect to the research, authorship, and/or publication of this article. 


\section{Funding}

The authors disclosed receipt of the following financial support for the research, authorship, and/or publication of this article: This research was supported by Stipendium Hungaricum Scholarship Program was launched by Hungarian Government; the program was managed by Tempus Public Foundation.

\section{ORCID iD}

Könül Karimova (iD) https://orcid.org/0000-0003-4840-3573

\section{References}

Abu-Hilal, M. M. (2005). Generality of self-perception models in Arab culture: Result from ten years of research. In H. Marsh, R. Craven, \& D. McInerney (Eds.), The new frontiers of self research (pp. 157-196). Information Age Publishing.

Abu-Hilal, M. M., Abdelfattah, F. A., Alshumrani, S. A., Abduljabbar, A. S., \& Marsh, H. W. (2013). Construct validity of self-concept in TIMSS's student background questionnaire: A test of separation and conflation of cognitive and affective dimensions of self-concept among Saudi eighth graders. European Journal of Psychology of Education, 28, 12011220. http://dx.doi.org/10.1007/s10212-012-0162-1

Arens, A. K., \& Jansen, M. (2016). Self-concepts in reading, writing, listening and speaking: A multidimensional and hierarchical structure and its generalizability across native and foreign languages. Journal of Educational Psychology, 108(5), 646-664. https://doi. org/10.1037/edu0000081

Arens, A. K., Jansen, M., Preckel, F., Schmidt, I., \& Brunner, M. (2020). The structure of academic self-concept: A methodological review and empirical illustration of central models. Review of Educational Research, 10(20), 1-39. https://doi.org/10.3102/0034654320972186

Arens, A. K., Yeung, A. S., Craven, R. G., \& Hasselhorn, M. (2011). The twofold multidimensionality of academic self-concept: Domain specificity and separation between competence and affect components. Journal of Educational Psychology, 103(4), 970-981. https://doi. org/10.1037/a0025047

Arens, A. K., Yeung, A. S., Craven, R. G., \& Hasselhorn, M. (2013). A short German version of the Self-Description Questionnaire I: Theoretical and empirical comparability. International Journal of Research and Method in Education, 36(4), 415-438. https://doi. org/10.1080/1743727X.2012.710503

Arens, A. K., Yeung, A. S., \& Hasselhorn, M. (2014). Native language self-concept and reading self-concept: Same or different? Journal of Experimental Education, 82(2), 229-252. https://doi.org/10.1080/00220973.2013.813362

Aunola, K., Leskinen, E., Onatsu-Arvilommi, T., \& Nurmi, J.-E. (2002). Three methods for studying developmental change: A case of reading skills and self-concept. British Journal of Educational Psychology, 72(3), 343-364. https://doi.org/10.1348/000709902320634447

Bong, M. (1998). Tests of the internal/external frames of reference model with subject-specific academic self-efficacy and frame-specific academic self-concepts. Journal of Educational Psychology, 90(1), 102-110. https://doi.org/10.1037/0022-0663.90.1.102

Bong, M., \& Skaalvik, E. M. (2003). Academic self-concept and self-efficacy: How different are they really? Educational Psychology Review, 15(1), 1-40. https://doi. org/10.1023/A:1021302408382

Browne, M. W., \& Cudeck, R. (1993). Alternative ways of assessing model fit. In K. A. Bollen \& J. S. Long (Eds.), Testing structural equation models (pp. 136-162). SAGE. 
Calsyn, R. J., \& Kenny, D. A. (1977). Self-concept of ability and perceived evaluation of others: Cause or effect of academic achievement? Journal of Educational Psychology, 69(2), 136-145. https://doi.org/10.1037/0022-0663.69.2.136

Cényelvi mérés. (2013/2014). feladatsorok és javitókulcsok [2013/2014 assessment of target languages: Test booklets and keys]. https://www.oktatas.hu/kozneveles/meresek/celnyelvi_meres/feladatsorok/celnymeres_2014

Chapman, J. W., \& Tunmer, W. E. (1995). Development of young children's reading selfconcepts: An examination of emerging subcomponents and their relationship with reading achievement. Journal of Educational Psychology, 87(1), 154-167. https://doi. org/10.1037/0022-0663.87.1.154

Chapman, J. W., \& Tunmer, W. E. (1997). A longitudinal study of beginning reading achievement and reading self-concept. British Journal of Educational Psychology, 67(3), 279-291. https://doi.org/10.1111/j.2044-8279.1997.tb01244.x

Chapman, J. W., \& Tunmer, W. E. (2003). Reading difficulties, reading-related self-perceptions, and strategies for overcoming negative self-beliefs. Reading and Writing Quarterly, 19(1), 5-24. https://doi.org/10.1080/10573560308205

Chen, F. F. (2007). Sensitivity of goodness of fit indexes to lack of measurement invariance. StructuralEquationModeling, 14(3),464-504.https://doi.org/10.1080/10705510701301834

Chen, F. F., Sousa, K. H., \& West, S. G. (2005). Testing measurement invariance of second-order factor models. Structural Equation Modeling, 12(3), 471-492. https://doi.org/10.1207/ s15328007sem1203 7

Conradi, K., Jang, B. G., \& McKenna, M. C. (2014). Motivation terminology in reading research: A conceptual review. Educational Psychology Review, 26, 127-164. https://doi. org/10.1007/s10648-013-9245-z

Council of Europe. (2001). Common European framework of reference for languages: Learning, teaching, assessment. Cambridge University Press.

Csapó, B. (2014). A szegedi iskolai longitudinális program [The Hungarian educational longitudinal program]. In J. Pál \& Z. Vajda (Eds.), Szegedi Egyetemi Tudástár 7Bölcsészet- és társadalomtudományok (pp. 117-166). Szegedi Egyetemi Kiadó.

Csapó, B., \& Molnár, G. (2019). Online diagnostic assessment in support of personalized teaching and learning: The eDia System. Frontiers in Psychology, 10, Article 1522. https://doi. org/10.3389/fpsyg.2019.01522

Csapó, B., \& Nikolov, M. (2009). The cognitive contribution to the development of proficiency in a foreign language. Learning and Individual Differences, 19(2), 209-218. https://doi. org/10.1016/j.lindif.2009.01.002

Deci, E. L., \& Ryan, R. M. (2000). The "what" and "why" of goal pursuits: Human needs and the self-determination of behavior. Psychological Inquiry, 11(4), 227-268. https://doi. org/10.1207/S15327965PLI1104_01

Eccles, J. S., \& Wigfield, A. (1995). In the mind of the actor: The structure of adolescents' achievement task values and expectancy-related beliefs. Personality and Social Psychology Bulletin, 21(3), 215-225. https://doi.org/10.1177/0146167295213003

Enders, C. K. (2010). Applied missing data analysis. Guilford Press.

Han, F. (2019). Self-concept and achievement in math among Australian primary students: Gender and cultural issues. Frontiers in Psychology, 10, Article 603. https://doi. org/10.3389/fpsyg.2019.00603

Hansford, B. C., \& Hattie, J. A. (1982). The relationship between self and achievement/ performance measures. Review of Educational Research, 52(1), 123-142. https://doi. org/10.2307/1170275 
Hu, L.-T., \& Bentler, P. M. (1995). Evaluating model fit. In R. H. Hoyle (Ed.), Structural equation modeling: Concepts, issues, and applications (pp. 76-99). SAGE.

Irwing, P. (1996). Evaluative and affective dimensions of self-concept: A test of construct validity using structural equations modeling. Psychological Reports, 79(3), 1127-1138. https:// doi.org/10.2466/pr0.1996.79.3f.1127

Jacobs, J. E., Lanza, S., Osgood, D. W., Eccles, J. S., \& Wigfield, A. (2002). Changes in children's self-competence and values: Gender and domain differences across grade one through twelve. Child Development, 73, 509-527. https://doi.org/10.1111/1467-8624.00421

Jansen, M. F., Scherer, R., \& Schroeders, U. (2015). Students' self-concept and self-efficacy in the sciences: Differential relations to antecedents and educational outcomes. Contemporary Educational Psychology, 41, 13-24. https://doi.org/10.1016/j.cedpsych.2014.11.002

Kasperski, R., Shany, M., \& Katzir, T. (2016). The role of RAN and reading rate in predicting reading self-concept. Reading and Writing, 29, 117-136. https://doi.org/10.1007/s11145015-9582-z

Katzir, T., Lesaux, N. K., \& Kim, Y.-S. (2009). The role of reading self-concept and home literacy practices in fourth grade reading comprehension. Reading and Writing: An Interdisciplinary Journal, 22(3), 261-276. https://doi.org/10.1007/s11145-007-9112-8

Kline, R. B. (2005). Methodology in the social sciences. Principles and practice of structural equation modeling (2nd ed.). Guilford Press.

Lafontine, D., Dupont, V., Jaegers, D., \& Schillings, P. (2019). Self-concept in reading: Factor structure, cross-cultural invariance and relationships with reading achievement in an international context (PIRLS 2011). Studies in Educational Evaluation, 60, 78-89. https://doi. org/10.1016/j.stueduc.2018.11.005

Marsh, H. W. (1986). Verbal and math self-concepts: An internal/external frame of reference model. American Educational Research Journal, 23, 129-149. https://doi.org/10.3102 $\% 2 \mathrm{~F} 00028312023001129$

Marsh, H. W. (1989). Age and sex effects in multiple dimensions of self-concept: Preadolescence to early adulthood. Journal of Educational Psychology, 81(3), 417-430. https://doi. org/10.1037/0022-0663.81.3.417

Marsh, H. W. (1990). Self-Description Questionnaire-II manual. University of Western Sydney.

Marsh, H. W. (1993). The multidimensional structure of academic self-concept: Invariance over gender and age. American Educational Research Journal, 30(4), 841-860. https://doi. org $/ 10.2307 / 1163206$

Marsh, H. W., \& Ayotte, V. (2003). Do multiple dimensions of self-concept become more differentiated with age? The differential distinctiveness hypothesis. Journal of Educational Psychology, 95(4), 687-706. https://doi.org/10.1037/0022-0663.95.4.687

Marsh, H. W., \& Craven, R. G. (1997). Academic self-concept: Beyond the dustbowl. In G. D. Phye (Ed.), Educational psychology series. Handbook of classroom assessment: Learning, achievement, and adjustment (pp. 131-198). Academic Press.

Marsh, H. W., \& Craven, R. G. (2006). Reciprocal effects of self-concept and performance from a multidimensional perspective: Beyond seductive pleasure and unidimensional perspectives. Perspectives on Psychological Science, 1(2), 133-163. https://doi.org/10.1111/ j.1745-6916.2006.00010.x

Marsh, H. W., Craven, R. G., \& Debus, R. (1998). Structure, stability, and development of young children's self-concepts: A multicohort-multioccasion study. Child Development, 69, 1030-1053. https://doi.org/10.1111/j.1467-8624.1998.tb06159.x

Marsh, H. W., Craven, R. G., \& Debus, R. (1999). Separation of competency and affect components of multiple dimensions of academic self-concept: A developmental perspective. Merrill-Palmer Quarterly, 45(4), 567-601. https://www.jstor.org/stable/23093373?seq=1 
Marsh, H. W., \& Hattie, J. (1996). Theoretical perspectives on the structure of self-concept. In B. A. Bracken (Ed.), Handbook of self-concept: Developmental, social, and clinical considerations (pp. 38-90). John Wiley.

Marsh, H. W., \& Hau, K.-T. (1996). Assessing goodness of fit: Is parsimony always desirable? Journal of Experimental Education, 64, 364-390. https://doi.org/10.1080/00220973.1996 .10806604

Marsh, H. W., \& Hau, K.-T. (2004). Explaining paradoxical relations between academic selfconcepts and achievements: Cross-cultural generalizability of the internal/external frame of reference predictions across 26 countries. Journal of Educational Psychology, 96(1), 56-67. https://doi.org/10.1037/0022-0663.96.1.56

Marsh, H. W., Hau, K.-T., \& Grayson, D. (2005). Goodness of fit in structural equation models. In A. Maydeu-Olivares \& J. J. McArdle (Eds.), Multivariate applications book series. Contemporary psychometrics: A festschrift for Roderick P. McDonald (pp. 275-340). Lawrence Erlbaum.

Marsh, H. W., \& Köller, O. (2004). Unification of theoretical models of academic self-concept/ achievement relations: Reunification of east and west German school systems after the fall of the Berlin Wall. Contemporary Educational Psychology, 29(3), 264-282. https://doi. org/10.1016/S0361-476X(03)00034-1

Marsh, H. W., Kuyper, H., Seaton Parker, P. D., Morin, A. J. S., Möller, J., \& Abduljabbar, A. S. (2014). Dimensional comparison theory: An extension of the internal/external frame of reference effect on academic self-concept formation. Contemporary Educational Psychology, 39, 326-341. https://doi.org/10.1016/j.cedpsych.2014.08.003

Marsh, H. W., Martin, A. J., \& Hau, K.-T. (2006). A multimethod perspective on self-concept research in educational psychology: A construct validity approach. In M. Eid \& E. Diener (Eds.), Handbook of multimethod measurement in psychology (pp. 441-456). American Psychological Association. https://doi.org/10.1037/11383-030

Marsh, H. W., Parker, P. D., Guo, J., Pekrun, R., \& Basarkod, G. (2020). Psychological comparison processes and self-concept in relation to five distinct frames of reference effects: Pan-human cross-cultural generalizability over 68 countries. European Journal of Personality, 34, 180-202. https://doi.org/10.1002/per.2232

Marsh, H. W., \& Shavelson, R. (1985). Self-concept: Its multifaceted, hierarchical structure. Educational Psychologist, 20, 107-123. https://doi.org/10.1207/s15326985ep2003_1

Marsh, H. W., Xu, M., \& Martin, A. J. (2012). Self-concept: A synergy of theory, method, and application. In K. R. G. Harris, T. Urdan, C. B. McCormick, G. M. Sinatra, \& J. Sweller (Eds.), APA educational psychology handbook (Vol. 1, pp. 427-458). American Psychological Association.

Marsh, H. W., \& Yeung, A. S. (1997). Causal effects of academic self-concept on academic achievement: Structural equation models of longitudinal data. Journal of Educational Psychology, 89(1), 41-54. https://doi.org/10.1037/0022-0663.89.1.41

Marsh, H. W., \& Yeung, A. S. (1998). Longitudinal structural equation models of academic self-concept and achievement: Gender differences in the development of math and English constructs. American Educational Research Journal, 35(4), 705-738. https://doi. org/10.2307/1163464

Millsap, R. E. (2011). Statistical approaches to measurement invariance. Routledge.

Ministry of Education of Azerbaijan Republic. (2010). The new curriculum of state standards of specific subject programs (Decision 103). Ministry of Education of Azerbaijan Republic. http://www.e-qanun.az/framework/19682 
Ministry of Education of Azerbaijan Republic. (2012). Notes of training planning (Decision 427). Ministry of Education of Azerbaijan Republic. https://edu.gov.az/upload/file/emreelave/2016/427/427-emre-elave11.pdf

Möller, J., \& Pohlmann, B. (2010). Achievement differences and self-concept differences: Stronger associations for above or below average students? British Journal of Educational Psychology, 80(3). https://doi.org/10.1348/000709909X485234

Möller, J., Pohlmann, B., Köller, O., \& Marsh, H. W. (2009). A meta-analytic path analysis of the internal/external frame of reference model of academic achievement and academic self-concept. Review of Educational Research, 79(3), 1129-1167. https://doi. org/10.3102\%2F0034654309337522

Möller, J., Retelsdorf, J., Köller, O., \& Marsh, H. W. (2011). The reciprocal internal/external frame of reference model an integration of models of relations between academic achievement and self-concept. American Educational Research Journal, 48, 1315-1346. https:// doi.org/10.3102\%2F0002831211419649

Morgan, P. L., \& Fuchs, D. (2007). Is there a bidirectional relationship between children's reading skills and reading motivation? Exceptional Children, 73(2), 165-183. https://doi. org/10.1177/001440290707300203

Muthén, L., \& Muthén, B. (1998-2015). Mplus user's guide (7th ed.).

Nikolov, M., \& Szabó, G. (2015). A study on Hungarian 6th and 8th graders' proficiency in English and German at dual-language schools. In D. Halló \& K. Károly (Eds.), Inspirations in foreign language teaching: Studies in applied linguistics. Language pedagogy and language teaching (pp. 184-206). Pearson Education.

Pajares, F., Miller, M. D., \& Johnson, M. J. (1999). Gender differences in writing self-beliefs of elementary school students. Journal of Educational Psychology, 91, 50-61. https://doi. org/10.1037/0022-0663.91.1.50

Parker, P. D., Marsh, H. W., Ciarrochi, J., Marshall, S., \& Abduljabbar, A. S. (2014). Juxtaposing math self-efficacy and self-concept as predictors of long-term achievement outcomes. Educational Psychology, 34(1), 29-48. https://doi.org/10.1080/01443410.2013.797339

Pinxten, M., Marsh, H. W., De Fraine, B., Van Den Noortgate, W., \& Van Damme, J. (2014). Enjoying mathematics or feeling competent in mathematics? Reciprocal effects on mathematics achievement and perceived math effort expenditure. British Journal of Educational Psychology, 84(1), 152-174. https://doi.org/10.1111/bjep.12028

Raykov, T. (2009). Evaluation of scale reliability for unidimensional measures using latent variable modeling. Measurement and Evaluation in Counseling and Development, 42(3), 223-232. https://doi.org/10.1177/0748175609344096

Retelsdorf, J., Köller, O., \& Möller, J. (2011). On the effects of motivation on reading performance growth in secondary school. Learning and Instruction, 21(4), 550-559. https://doi. org/10.1016/j.learninstruc.2010.11.001

Retelsdorf, J., Köller, O., \& Möller, J. (2014). Reading achievement and reading self-conceptTesting the reciprocal effects model. Learning and Instruction, 29, 21-30. https://doi. org/10.1016/j.learninstruc.2013.07.004

Rutkowski, L., Gonzalez, E., Joncas, M., \& von Davier, M. (2010). International large-scale assessment data: Issues in secondary analysis and reporting. Educational Researcher, 39(2), 142-151. https://doi.org/10.3102/0013189X10363170

Sass, D. A., \& Schmitt, T. A. (2013). Testing measurement and structural invariance. In T. Teo (Ed.), Handbook of quantitative methods for educational research (pp. 315-345). Sense Publishers. 
Schiefele, U., Schaffner, E., Möller, J., \& Wigfield, A. (2012). Dimensions of reading motivation and their relation to reading behavior and competence. Reading Research Quarterly, 47, 427-462. https://doi.org/10.1002/RRQ.030

Shafiyeva, U., \& Kennedy, S. (2010). English as a foreign language in Azerbaijan: English teaching in the post-Soviet era. English Today, 26(1), 9-14. https://doi.org/10.1017/ S0266078409990629

Shavelson, R. J., Hubner, J. J., \& Stanton, G. C. (1976). Self-concept: Validation of construct interpretations. Review of Educational Research, 46(3), 407-441. https://psycnet.apa.org/ doi/10.2307/1170010

Shavelson, R. J., \& Marsh, H. W. (1986). On the structure of self-concept. In R. Schwarzer (Ed.), Anxiety and cognitions (pp. 305-330). Lawrence Erlbaum.

Valentine, J. C., DuBois, D. L., \& Cooper, H. (2004). The relation between self-beliefs and academic achievement: A meta-analytic review. Educational Psychologist, 39(2), 111-133. https://doi.org/10.1207/s15326985ep3902_3

Wang, J., \& Wang, X. (2020). Structural equation modeling: Applications using Mplus (2nd ed.). John Wiley.

Warm, T. A. (1989). Weighted likelihood estimation of ability in item response theory. Psychometrika, 54, 427-450. https://doi.org/10.1007/BF02294627

Wigfield, A., \& Guthrie, J. T. (1997). Relations of children's motivation for reading to the amount and breadth of their reading. Journal of Educational Psychology, 89(3), 420-432. https://doi.org/10.1037/0022-0663.89.3.420

Wigfield, A., \& Karpathian, M. (1991). Who am I and what can I do? Children's self-concepts and motivation in achievement situations. Educational Psychologist, 26(3-4), 233-261. https://doi.org/10.1207/s15326985ep2603\&4_3

Wu, M. L., Adams, R. J., Wilson, M. R., \& Haldane, S. A. (2007). ACER ConQuest version 2.0: Generalised item response modelling software [Computer software]. ACER Press.

Xu, M. K., Marsh, H. W., Hau, K. T., Ho, I. T., Morin, A. S. J., \& Abduljabbar, A. S. (2013). The internal/external frame of reference of academic self-concept: Extension to a foreign language and the role of language of instruction. Journal of Educational Psychology, 105(2), 489-503. http://dx.doi.org/10.1037/a0031333

Yang, L., Arens, A. K., \& Watkins, D. A. (2014). Testing the twofold multidimensionality of academic self-concept: A study with Chinese vocational students. Educational Psychology, 36(9), 1651-1669. https://doi.org/10.1080/01443410.2014.995597

Yeung, A. S., \& Wong, E. K. P. (2004). Domain specificity of trilingual teachers' verbal self-concepts. Journal of Educational Psychology, 96(2), 360-368. http://dx.doi.org/10.1037/00220663.96.2.360

\section{About the Authors}

Könül Karimova is a $\mathrm{PhD}$ candidate in the Doctoral School of Education at the University of Szeged. Her research interest includes teaching and learning languages, academic self-concept and educational evaluation.

Benö Csapó is a professor of Education at the University of Szeged, the head of the Center for Research on Learning and Instruction and the Research Group on the Development of Competencies, Hungarian Academy of Sciences. His research interests are in cognitive development, educational evaluation and technology-based assessment. 